\title{
World Federation of Critical Care Nurses sub-committee for the position statement: guidelines on nursing workforce requirements for the care of critically ill patients
}

The WFCCN is looking for critical care nurses with expertise and knowledge in the development of workforce guidelines for critical care nursing. The attached Terms of Reference are provided for information.

The basic process to be followed will be to:

1. Gather copies of staffing documents from around the world that explain nursing/critical care workforce requirements.

2. Identify a template/format that would be appropriate to use.

3. Draft a few options and discussion paper and circulate for comment from the interested persons.

4. Table draft at the WFCCN meeting in Cambridge (September 2004) or workshop the document if needed.

5. $\quad$ Finalise document by end of 2004

6. Publish in 2005 and present full findings at 9th World Congress on Intensive Care in Argentina, August 2005.

ANY INTERESTED PERSONS should contact Ged Williams (President WFCCN) by E-mail: ged.williams@mh.org.au

\section{TERMS OF REFERENCE}

Role of Committee

To disseminate relevant information to members of the committee and establish an understanding of the workforce standards common to most member countries using the BACCN and ACCCN standards as a starting point if deemed relevant.

To discuss, recommend and provide a position statement with concepts relevant to the issue and present them in a format that is simple to follow, succinct and practical. In addition they must be easy to read for those who have English as a second language. The guidelines must be interpretable for small and impoverished countries to follow within their own context and circumstances. Ideally the document should fit on an A4 size sheet of paper with no less than size 12 font text.

Receive and consider feedback from a large range of stakeholders and maintain records of consultations and drafts so that an orderly trail is kept for future reflection.

Provide a final draft Position Statement with recommendations for the WFCCN to consider by June 2004 .

Review feedback and requirements of the WFCCN on the final draft after September 2004 and finalise and disseminate the position statement internationally through the WFCCN by early 2005 .

\begin{abstract}
Membership
At least two members of the WFCCN Council are to be members of the group. A call for representatives from member countries will be initiated by the Chair to establish a broad and representative consultation team.

Any other members with specific expertise in non-member countries may be consulted but will not have decision-making powers.

\section{Communication and cost}

Communication will be via email, fax or phone and at the expense of the participant members, their employers or critical care association. WFCCN will not pay for any costs in the development stage. Once a final product is developed and approved the committee may wish to advise on possible dissemination strategies and provide a modest budget for consideration if necessary.
\end{abstract}

\section{Chairperson}

Must be a WFCCN Council member or any other person endorsed by the WFCCN Council. This position may be co-facilitated should more than one person agree to share this role.

\section{Secretary}

A WFCCN Council member or Chair must accept responsibility for this role but may delegate the role to others provide minutes and drafts are centrally kept and accounted for.

\section{Reporting mechanism/minutes}

The Committee reports to WFCCN Council through the Chair (or WFCCN Council member).

This is to be via email unless opportunistic meetings are available at other times.

\section{OBJECTIVES}

* To identify existing workforce standards for critical care nurses.

* To plan, discuss and draft internationally acceptable concepts, statements or guidelines to inform the minimum workforce requirements for nurses who care for critically ill patients. 
* To formalise recommendations for the WFCNN by June 2004 so that they can be considered by the WFCCN Council in September 2004.

* To receive, accept and modify draft documents according to WFCCN feedback.
* To disseminate and market the final WFCCN Position Statement: Guidelines on Nursing Workforce Requirements for the Care of Critically III Patients by July 2005. 